\title{
On Intuitionistic Fuzzy $\pi$ - Generalized Semi Continuous Mappings
}

\author{
S. Maragathavalli \\ Assistant Professor, Department of Mathematics \\ Sree Saraswathi thyagaraja College \\ Pollachi, Tamil Nadu (INDIA)
}

\author{
K. Ramesh \\ Assistant Professor, Department of Mathematics \\ S.V.S College of Engineering \\ Coimbatore, Tamil Nadu (INDIA)
}

\begin{abstract}
In this paper we have introduced intuitionistic fuzzy $\pi$ - generalized semi continuous mappings and some of their basic properties are studied.
\end{abstract}

\section{Keywords}

Intuitionistic fuzzy topology, intuitionistic fuzzy $\pi$ generalized semi closed sets, intuitionistic fuzzy $\pi$ generalized semi continuous mappings, intuitionistic fuzzy $\pi \mathrm{T}_{1 / 2}\left(\mathrm{IF}_{\pi} \mathrm{T}_{1 / 2}\right)$ space and intuitionistic fuzzy $\pi \mathrm{gT}_{1 / 2}\left(\mathrm{IF} \pi \mathrm{gT}_{1 / 2}\right.$ ) space.

\section{AMS SUBJECT CLASSIFICATION (2000): \\ 54A40, 03F55}

\section{INTRODUCTION}

The concept of fuzzy sets was introduced by Zadeh [13] and later Atanassov [1] generalized this idea to intuitionistic fuzzy sets using the notion of fuzzy sets. On the other hand Coker [4] introduced intuitionistic fuzzy topological spaces using the notion of intuitionistic fuzzy sets. In this paper, we introduce intuitionistic fuzzy $\pi$ - generalized semi continuous mappings and studied some of their basic properties. We arrive at some characterizations of intuitionistic fuzzy $\pi$ - generalized semi continuous mappings.

\section{PRELIMINARIES}

Definition 2.1: [1] Let $X$ be a non empty fixed set. An intuitionistic fuzzy set (IFS in short) $\mathrm{A}$ in $\mathrm{X}$ is an object having the form $\mathrm{A}=\left\{\left\langle\mathrm{x}, \mu_{\mathrm{A}}(\mathrm{x}), v_{\mathrm{A}}(\mathrm{x})\right\rangle / \mathrm{x} \in \mathrm{X}\right\}$ where the functions $\mu_{\mathrm{A}}(\mathrm{x}): \mathrm{X} \rightarrow[0,1]$ and $v_{\mathrm{A}}(\mathrm{x}): \mathrm{X} \rightarrow[0,1]$ denote the degree of membership (namely $\mu_{A}(x)$ ) and the degree of non membership (namely $v_{\mathrm{A}}(\mathrm{x})$ ) of each element $\mathrm{x} \in \mathrm{X}$ to the set A, respectively and $0 \leq \mu_{A}(x)+v_{A}(x) \leq 1$ for each $x \in X$. Denote the set of all intuitionistic fuzzy sets in $\mathrm{X}$ by IFS (X).

Definition 2.2: [1] Let A and B be IFS's of the form $\mathrm{A}=\left\{\left\langle\mathrm{x}, \mu_{\mathrm{A}}(\mathrm{x}), v_{\mathrm{A}}(\mathrm{x})\right\rangle / \mathrm{x} \in \mathrm{X}\right\}$ and

$\mathrm{B}=\left\{\left\langle\mathrm{x}, \mu_{\mathrm{B}}(\mathrm{x}), v_{\mathrm{B}}(\mathrm{x})\right\rangle / \mathrm{x} \in \mathrm{X}\right\}$. Then

(a) $\mathrm{A} \subseteq \mathrm{B}$ if and only if $\mu_{\mathrm{A}}(\mathrm{x}) \leq \mu_{\mathrm{B}}(\mathrm{x})$ and $v_{\mathrm{A}}(\mathrm{x}) \geq v_{\mathrm{B}}(\mathrm{x})$ for all $\mathrm{x} \in \mathrm{X}$, (b) A = B if and only if $\mathrm{A} \subseteq \mathrm{B}$ and $\mathrm{B} \subseteq \mathrm{A}$,

(c) $\mathrm{A}^{\mathrm{c}}=\left\{\left\langle\mathrm{x}, v_{\mathrm{A}}(\mathrm{x}), \mu_{\mathrm{A}}(\mathrm{x})\right\rangle / \mathrm{x} \in \mathrm{X}\right\}$,

(d) $\mathrm{A} \cap \mathrm{B}=\left\{\left\langle\mathrm{x}, \mu_{\mathrm{A}}(\mathrm{x}) \wedge \mu_{\mathrm{B}}(\mathrm{x}), v_{\mathrm{A}}(\mathrm{x}) \vee v_{\mathrm{B}}(\mathrm{x})\right\rangle / \mathrm{x} \in \mathrm{X}\right\}$,

(e) $\mathrm{A} \cup \mathrm{B}=\left\{\left\langle\mathrm{x}, \mu_{\mathrm{A}}(\mathrm{x}) \vee \mu_{\mathrm{B}}(\mathrm{x}), v_{\mathrm{A}}(\mathrm{x}) \wedge v_{\mathrm{B}}(\mathrm{x})\right\rangle / \mathrm{x} \in \mathrm{X}\right\}$.

For the sake of simplicity, we shall use the notation $\mathrm{A}=\left\langle\mathrm{x}, \mu_{\mathrm{A}}, v_{\mathrm{A}}\right\rangle$ instead of $\mathrm{A}=\left\{\left\langle\mathrm{x}, \mu_{\mathrm{A}}(\mathrm{x}), v_{\mathrm{A}}(\mathrm{x})\right\rangle / \mathrm{x} \in \mathrm{X}\right\}$. Also for the sake of simplicity, we shall use the notation $\mathrm{A}=\left\langle\mathrm{x},\left(\mu_{\mathrm{A}}, \mu_{\mathrm{B}}\right),\left(v_{\mathrm{A}}, v_{\mathrm{B}}\right)\right\rangle$ instead of $\mathrm{A}=\left\langle\mathrm{x},\left(\mathrm{A} / \mu_{\mathrm{A}}, \mathrm{B} / \mu_{\mathrm{B}}\right),\left(\mathrm{A} / v_{\mathrm{A}}, \mathrm{B} / v_{\mathrm{B}}\right)\right\rangle$.

The intuitionistic fuzzy sets $0_{\sim}=\{\langle\mathrm{x}, 0,1\rangle / \mathrm{x} \in \mathrm{X}\}$ and $1_{\sim}=\{\langle\mathrm{x}, 1,0\rangle / \mathrm{x} \in \mathrm{X}\}$ are respectively the empty set and the whole set of $X$.

Definition 2.3: [3] An intuitionistic fuzzy topology (IFT in short) on a non empty $\mathrm{X}$ is a family $\tau$ of IFS in $\mathrm{X}$ satisfying the following axioms:

(a) $0_{\sim}, 1_{\sim} \in \tau$

(b) $\mathrm{G}_{1} \cap \mathrm{G}_{2} \in \tau$, for any $\mathrm{G}_{1}, \mathrm{G}_{2} \in \tau$

(c) $\cup \mathrm{G}_{\mathrm{i}} \in \tau$ for any arbitrary family $\left\{\mathrm{G}_{\mathrm{i}} / \mathrm{i} \in \mathrm{J}\right\} \subseteq \tau$.

In this case the pair $(\mathrm{X}, \tau)$ is called an intuitionistic fuzzy topological space (IFTS in short) and any IFS in $\tau$ is known as an intuitionistic fuzzy open set (IFOS for short) in X.

The complement $\mathrm{A}^{\mathrm{c}}$ of an IFOS $\mathrm{A}$ in an IFTS $(\mathrm{X}, \tau)$ is called an intuitionistic fuzzy closed set (IFCS for short) in X.

Definition 2.4: [3] Let $(X, \tau)$ be an IFTS and $A=\left\langle x, \mu_{A}, v_{A}\right\rangle$ be an IFS in $X$. Then the intuitionistic fuzzy interior and an intuitionistic fuzzy closure are defined by

$\operatorname{int}(\mathrm{A})=\cup\{\mathrm{G} / \mathrm{G}$ is an IFOS in $\mathrm{X}$ and $\mathrm{G} \subseteq \mathrm{A}\}$,

$\operatorname{cl}(\mathrm{A})=\cap\{\mathrm{K} / \mathrm{K}$ is an IFCS in $\mathrm{X}$ and $\mathrm{A} \subseteq \mathrm{K}\}$.

Note that for any IFS $A$ in $(X, \tau)$, we have $\operatorname{cl}\left(A^{c}\right)=[\operatorname{int}(A)]^{c}$ and $\operatorname{int}\left(\mathrm{A}^{\mathrm{c}}\right)=[\mathrm{cl}(\mathrm{A})]^{\mathrm{c}}$.

Definition 2.5: [7] An IFS $A=\left\{\left\langle x, \mu_{A}, v_{A}\right\rangle\right\}$ in an IFTS (X, $\tau)$ is said to be an

(i) intuitionistic fuzzy semi open set (IFSOS in short) if $\mathrm{A} \subseteq \operatorname{cl}(\operatorname{int}(\mathrm{A}))$

(ii) intuitionistic fuzzy $\alpha$-open set (IF $\alpha \mathrm{OS}$ in short) if $\mathrm{A} \subseteq \operatorname{int}(\operatorname{cl}(\operatorname{int}(\mathrm{A})))$, 
(iii) intuitionistic fuzzy regular open set (IFROS in short) if $\mathrm{A}=\operatorname{int}(\mathrm{cl}(\mathrm{A}))$.

The family of all IFOS (respectively IFSOS, IF $\alpha$ OS, IFROS) of an IFTS $(\mathrm{X}, \tau)$ is denoted by $\operatorname{IFO}(\mathrm{X})$ (respectively $\operatorname{IFSO}(\mathrm{X}), \operatorname{IF} \alpha \mathrm{O}(\mathrm{X}), \operatorname{IFRO}(\mathrm{X})$ ).

Definition 2.6: [7] An IFS $A=\left\langle x, \mu_{A}, v_{A}\right\rangle$ in an IFTS (X, $\tau$ ) is said to be an

(i) intuitionistic fuzzy semi closed set (IFSCS in short) if $\operatorname{int}(\operatorname{cl}(\mathrm{A})) \subseteq \mathrm{A}$,

(ii) intuitionistic fuzzy $\alpha$-closed set (IF $\alpha \mathrm{CS}$ in short) if $\operatorname{cl}(\operatorname{int}(\operatorname{cl}(\mathrm{A})) \subseteq \mathrm{A}$,

(iii) intuitionistic fuzzy regular closed set (IFRCS in short) if $\mathrm{A}=\operatorname{cl}(\operatorname{int}((\mathrm{A})$.

The family of all IFCS (respectively IFSCS, IF $\alpha$ CS, IFRCS) of an IFTS $(\mathrm{X}, \tau)$ is denoted by $\operatorname{IFC}(\mathrm{X})$ (respectively $\operatorname{IFSC}(\mathrm{X})$, $\operatorname{IF} \alpha \mathrm{C}(\mathrm{X}), \operatorname{IFRC}(\mathrm{X})$ ).

Definition 2.7: [12] Let A be an IFS in an IFTS $(X, \tau)$. Then

$\operatorname{sint}(A)=\cup\{G / G$ is an IFSOS in $X$ and $G \subseteq A\}$,

$\operatorname{scl}(\mathrm{A})=\cap\{\mathrm{K} / \mathrm{K}$ is an IFSCS in $\mathrm{X}$ and $\mathrm{A} \subseteq \mathrm{K}\}$.

Note that for any IFS $A$ in $(X, \tau)$, we have $\operatorname{scl}\left(A^{c}\right)=(\operatorname{sint}(A))^{c}$ and $\operatorname{sint}\left(\mathrm{A}^{\mathrm{c}}\right)=(\operatorname{scl}(\mathrm{A}))^{\mathrm{c}}$.

Definition 2.8:[11] An IFS A in an IFTS $(X, \tau)$ is an

(i) intuitionistic fuzzy generalized closed set (IFGCS in short) if $\operatorname{cl}(\mathrm{A}) \subseteq \mathrm{U}$ whenever $\mathrm{A} \subseteq \mathrm{U}$ and $\mathrm{U}$ is an IFOS in $\mathrm{X}$.

(ii) intuitionistic fuzzy regular generalized closed set (IFRGCS in short) if $\operatorname{cl}(\mathrm{A}) \subseteq \mathrm{U}$ whenever $\mathrm{A} \subseteq \mathrm{U}$ and $\mathrm{U}$ is an IFROS in $\mathrm{X}$.

Definition 2.9:[10] An IFS A in an IFTS $(X, \tau)$ is said to be an intuitionistic fuzzy generalized semi closed set (IFGSCS in short) if $\operatorname{scl}(\mathrm{A}) \subseteq \mathrm{U}$ whenever $\mathrm{A} \subseteq \mathrm{U}$ and $\mathrm{U}$ is an IFOS in $(\mathrm{X}, \tau)$.

Definition 2.10:[10] An IFS A is said to be an intuitionistic fuzzy generalized semi open set (IFGSOS in short) in $\mathrm{X}$ if the complement $A^{c}$ is an IFGSCS in $\mathrm{X}$.

The family of all IFGSCSs (IFGSOSs) of an IFTS $(\mathrm{X}, \tau)$ is denoted by IFGSC(X) (IFGSO(X)).

Definition 2.11:[8] An IFS A in an IFTS $(X, \tau)$ is said to be an intuitionistic fuzzy $\pi$ - generalized semi closed set (IF-GSCS in short) if $\operatorname{scl}(\mathrm{A}) \subseteq \mathrm{U}$ whenever $\mathrm{A} \subseteq \mathrm{U}$ and $\mathrm{U}$ is an IFrIOS in $(\mathrm{X}, \tau)$.
Result 2.12:[8] Every IFCS, IFGCS, IFRCS, IF $\alpha C S$, IFGSCS is an IF-GSCS but the converses may not be true in general. Every IF $\alpha \mathrm{GCS}$ is IFGSCS but the converse is need not be true.

Definition 2.13:[9] An IFS A is said to be an intuitionistic fuzzy alpha generalized open set (IF $\alpha \mathrm{GOS}$ in short) in $\mathrm{X}$ if the complement $A^{c}$ is an IF $\alpha$ GCS in X.The family of all IF $\alpha$ GCSs (IF $\alpha \mathrm{GOSs})$ of an IFTS $(\mathrm{X}, \tau)$ is denoted by $\operatorname{IF} \alpha \mathrm{GC}(\mathrm{X})(\mathrm{IF} \alpha \mathrm{GO}(\mathrm{X}))$.

Definition 2.14:[5] Let $\mathrm{f}$ be a mapping from an IFTS $(\mathrm{X}, \tau)$ into an IFTS $(\mathrm{Y}, \sigma)$. Then $\mathrm{f}$ is said to be intuitionistic fuzzy continuous (IF continuous in short) if $\mathrm{f}^{-1}(\mathrm{~B}) \in \mathrm{IFO}(\mathrm{X})$ for every $\mathrm{B} \in \sigma$.

Definition 2.15:[7] Let $\mathrm{f}$ be a mapping from an IFTS $(\mathrm{X}, \tau)$ into an IFTS $(Y, \sigma)$. Then $f$ is said to be

(i) intuitionistic fuzzy semi continuous (IFS continuous in short) if $\mathrm{f}^{-1}(\mathrm{~B}) \in \operatorname{IFSO}(\mathrm{X})$ for every $\mathrm{B} \in \sigma$.

(ii) intuitionistic fuzzy $\alpha$ - continuous (IF $\alpha$ continuous in short) if $\mathrm{f}^{-1}(\mathrm{~B}) \in \mathrm{IF \alpha O}(\mathrm{X})$ for every $\mathrm{B} \in \sigma$.

(iii) intuitionistic fuzzy pre continuous (IFP continuous in short) if $\mathrm{f}^{-1}(\mathrm{~B}) \in \operatorname{IFPO}(\mathrm{X})$ for every $\mathrm{B} \in \sigma$.

Result 2.16:[7] Every IF continuous mapping is an IF $\alpha$-continuous mapping and every IF $\alpha$-continuous mapping is an IFS continuous mapping.

Definition 2.17:[6] A mapping $\mathrm{f}:(\mathrm{X}, \tau) \rightarrow(\mathrm{Y}, \sigma)$ is called an intuitionistic fuzzy $\gamma$ continuous (IF $\gamma$ continuous in short) if $\mathrm{f}^{-1}(\mathrm{~B})$ is an IF $\gamma \mathrm{OS}$ in $(\mathrm{X}, \tau)$ for every $\mathrm{B} \in \sigma$.

Definition 2.18:[10] Let $\mathrm{f}$ be a mapping from an IFTS (X, $\tau)$ into an IFTS $(\mathrm{Y}, \sigma)$. Then $\mathrm{f}$ is said to be an intuitionistic fuzzy generalized continuous (IFG continuous in short) if $\mathrm{f}^{-1}(\mathrm{~B}) \in \operatorname{IFGCS}(\mathrm{X})$ for every IFCS B in $\mathrm{Y}$.

Result 2.19:[10] Every IF continuous mapping is an IFG continuous mapping.

Definition 2.20:[9] A mapping f: $(\mathrm{X}, \tau) \rightarrow(\mathrm{Y}, \sigma)$ is called an intuitionistic fuzzy generalized semi continuous (IFGS continuous in short) if $\mathrm{f}^{-1}(\mathrm{~B})$ is an IFGSCS in $(\mathrm{X}, \tau)$ for every $\operatorname{IFCS} \mathrm{B}$ of $(\mathrm{Y}, \sigma)$.

Definition 2.21:[8] An IFTS $(X, \tau)$ is said to be an intuitionistic fuzzy $\pi \mathrm{T}_{1 / 2}$ (IF $\pi \mathrm{T}_{1 / 2}$ in short) space if every IF $\pi$ GSCS in $\mathrm{X}$ is an IFCS in $\mathrm{X}$.

Definition 2.22:[8] An IFTS $(X, \tau)$ is said to be an intuitionistic fuzzy $\pi \mathrm{gT}_{1 / 2}$ (IF $\pi \mathrm{gT}_{1 / 2}$ in short) space if every $\mathrm{IF} \pi \mathrm{GSCS}$ in $\mathrm{X}$ is an IFGCS in $\mathrm{X}$. 


\section{INTUITIONISTIC FUZZY}

\section{$\pi$ - GENERALIZED SEMI CONTINUOUS}

\section{MAPPINGS}

In this section we have introduced intuitionistic fuzzy $\pi$ - generalized continuous mapping and studied some of its properties.

Definition 3.1: A mapping f: $(X, \tau) \rightarrow(Y, \sigma)$ is called an intuitionistic fuzzy $\pi$ - generalized semi continuous (IF-GS continuous in short) if $\mathrm{f}^{-1}(\mathrm{~B})$ is an $\operatorname{IF} \overline{\mathrm{ESSCS}}$ in $(\mathrm{X}, \tau)$ for every IFCS B of $(Y, \sigma)$.

Example 3.2: Let $X=\{a, b\}, Y=\{u, v\}$ and $G_{1}=\langle x,(0.4$, $0.2),(0.6,0.7)\rangle, \mathrm{G}_{2}=\langle\mathrm{y},(0.7,0.8),(0.3,0.2)\rangle$. Then $\tau=\left\{0_{\sim}\right.$, $\mathrm{G}_{1,1} 1_{\sim}$ and $\sigma=\left\{0_{\sim}, \mathrm{G}_{2}, 1_{\sim}\right\}$ are IFTs on $\mathrm{X}$ and $\mathrm{Y}$ respectively. Define a mapping $\mathrm{f}:(\mathrm{X}, \tau) \rightarrow(\mathrm{Y}, \sigma)$ by $\mathrm{f}(\mathrm{a})=\mathrm{u}$ and $\mathrm{f}(\mathrm{b})=\mathrm{v}$. Then $\mathrm{f}$ is an IFrGS continuous mapping.

Theorem 3.3: Every IF continuous mapping is an IFrGS continuous mapping but not conversely.

Proof: Let $\mathrm{f}:(\mathrm{X}, \tau) \rightarrow(\mathrm{Y}, \sigma)$ be an IF continuous mapping. Let $A$ be an IFCS in Y. Since $f$ is IF continuous mapping, $f^{-}$ ${ }^{1}(\mathrm{~A})$ is an IFCS in X. Since every IFCS is an IFmGSCS, $\mathrm{f}$ ${ }^{1}$ (A) is an IF-GSCS in $\mathrm{X}$. Hence $\mathrm{f}$ is an IF-GS continuous mapping.

Example 3.4: Let $X=\{a, b\}, Y=\{u, v\}$ and $G_{1}=\langle x,(0.1$, $0.1),(0.8,0.6)\rangle, \mathrm{G}_{2}=\langle\mathrm{y},(0.8,0.6),(0.1,0.1)\rangle$. Then $\tau=\left\{0_{\sim}\right.$, $\left.\mathrm{G}_{1,} 1_{\sim}\right\}$ and $\sigma=\left\{0_{\sim}, \mathrm{G}_{2}, 1_{\sim}\right\}$ are IFTs on $\mathrm{X}$ and $\mathrm{Y}$ respectively. Define a mapping $\mathrm{f}:(\mathrm{X}, \tau) \rightarrow(\mathrm{Y}, \sigma)$ by $\mathrm{f}(\mathrm{a})=\mathrm{u}$ and $\mathrm{f}(\mathrm{b})=\mathrm{v}$. The IFS $\mathrm{G}_{2}{ }^{\mathrm{c}}=\langle\mathrm{y},(0.1,0.1),(0.8,0.6)\rangle$ is IFCS in Y. Then $\mathrm{f}^{-1}\left(\mathrm{G}_{2}{ }^{\mathrm{c}}\right)$ is IF-GSCS in $\mathrm{X}$ but not IFCS in $\mathrm{X}$. Therefore $\mathrm{f}$ is an IF-GS continuous mapping but not an IF continuous mapping.

Theorem 3.5: Every IF $\alpha$ continuous mapping is an IF-GS continuous mapping but not conversely.

Proof: Let $\mathrm{f}:(\mathrm{X}, \tau) \rightarrow(\mathrm{Y}, \sigma)$ be an IF $\alpha$ continuous mapping. Let $\mathrm{A}$ be an IFCS in Y. Then $\mathrm{f}^{-1}(\mathrm{~A})$ is an IF $\alpha \mathrm{CS}$ in $\mathrm{X}$. Since every IF $\alpha C S$ is an IF-GSCS, $\mathrm{f}^{-1}(\mathrm{~A})$ is an IFMGSCS in $\mathrm{X}$. Hence $\mathrm{f}$ is an $\mathrm{IF}-\mathrm{GS}$ continuous mapping.

Example 3.6: Let $X=\{a, b\}, Y=\{u, v\}$ and $G_{1}=\langle x,(0.7$, $0.8),(0.3,0.1)\rangle, \mathrm{G}_{2}=\langle\mathrm{y},(0.2,0.3),(0.5,0.4)\rangle$. Then $\tau=\left\{0_{\sim}\right.$, $\left.\mathrm{G}_{1,1}\right\}$ and $\sigma=\left\{0_{\sim}, \mathrm{G}_{2,1}\right\}$ are IFTs on $\mathrm{X}$ and $\mathrm{Y}$ respectively. Define a mapping $\mathrm{f}:(\mathrm{X}, \tau) \rightarrow(\mathrm{Y}, \sigma)$ by $\mathrm{f}(\mathrm{a})=\mathrm{u}$ and $\mathrm{f}(\mathrm{b})=\mathrm{v}$. The IFS $\mathrm{G}_{2}{ }^{\mathrm{c}}=\langle\mathrm{y},(0.5,0.4),(0.2,0.3)\rangle$ is IFCS in Y. Then $\mathrm{f}^{-1}\left(\mathrm{G}_{2}{ }^{\mathrm{c}}\right)$ is IF-GSCS in $\mathrm{X}$ but not IF $\alpha \mathrm{CS}$ in $\mathrm{X}$. Then $\mathrm{f}$ is IF-GS continuous mapping but not an IF $\alpha$ continuous mapping.
Theorem 3.7: Every IFR continuous mapping is an IFrGS continuous mapping but not conversely.

Proof: Let $\mathrm{f}:(\mathrm{X}, \tau) \rightarrow(\mathrm{Y}, \sigma)$ be an IFR continuous mapping. Let $A$ be an IFCS in $Y$. Then by hypothesis $f^{-1}(A)$ is an IFRCS in X. Since every IFRCS is an IFmGSCS, $\mathrm{f}^{-1}(\mathrm{~A})$ is an IF-GSCS in $\mathrm{X}$. Hence $\mathrm{f}$ is an IFMGS continuous mapping.

Example 3.8: Let $X=\{a, b\}, Y=\{u, v\}$ and $G_{1}=\langle x,(0.3$, $0.4),(0.5,0.6)\rangle, \mathrm{G}_{2}=\langle\mathrm{y},(0.5,0.6),(0.3,0.4)\rangle$. Then $\tau=\left\{0_{\sim}\right.$, $\left.\mathrm{G}_{1,1} 1_{\sim}\right\}$ and $\sigma=\left\{0_{\sim}, \mathrm{G}_{2,1},\right\}$ are IFTs on $\mathrm{X}$ and $\mathrm{Y}$ respectively. Define a mapping $\mathrm{f}:(\mathrm{X}, \tau) \rightarrow(\mathrm{Y}, \sigma)$ by $\mathrm{f}(\mathrm{a})=\mathrm{u}$ and $\mathrm{f}(\mathrm{b})=\mathrm{v}$. The IFS $\mathrm{G}_{2}{ }^{\mathrm{c}}=\langle\mathrm{y},(0.3,0.4),(0.5,0.6)\rangle$ is IFCS in $\mathrm{Y}$. Then $\mathrm{f}^{-1}\left(\mathrm{G}_{2}{ }^{\mathrm{c}}\right)$ is IF-GSCS in $\mathrm{X}$ but not IFRCS in $\mathrm{X}$. Then $\mathrm{f}$ is IFrGS continuous mapping but not an IFR continuous mapping.

Theorem 3.9: Every IFG continuous mapping is an IF-GS continuous mapping but not conversely.

Proof: Let $\mathrm{f}:(\mathrm{X}, \tau) \rightarrow(\mathrm{Y}, \sigma)$ be an IFG continuous mapping. Let $A$ be an IFCS in Y. Since $f$ is an IFG continuous mapping, $\mathrm{f}^{-1}(\mathrm{~A})$ is an IFGCS in X. Since every IFGCS is an IF-GSCS, $\mathrm{f}^{-1}(\mathrm{~A})$ is an IFmGSCS in $\mathrm{X}$. Hence $\mathrm{f}$ is an IFmGS continuous mapping.

Example 3.10: Let $X=\{a, b\}, Y=\{u, v\}$ and $G_{1}=\langle x$, $(0.2,0.8),(0.3,0.1)\rangle, \mathrm{G}_{2}=\langle\mathrm{y},(0.2,0.3),(0.5,4)\rangle$. Then $\tau=\{$ $\left.0_{\sim}, \mathrm{G}_{1}, 1_{\sim}\right\}$ and $\sigma=\left\{0_{\sim}, \mathrm{G}_{2}, 1_{\sim}\right\}$ are IFTs on $\mathrm{X}$ and $\mathrm{Y}$ respectively. Define a mapping $\mathrm{f}:(\mathrm{X}, \tau) \rightarrow(\mathrm{Y}, \sigma)$ by $\mathrm{f}(\mathrm{a})=\mathrm{u}$ and $f(b)=v$. Then $f$ is an IF-GS continuous mapping. Now consider the IFCS $\mathrm{G}_{2}{ }^{\mathrm{c}}=\langle\mathrm{y},(0.5,0.4),(0.2,0.3)\rangle$ in $\mathrm{Y}$. Then $\mathrm{f}^{-1}\left(\mathrm{G}_{2}{ }^{\mathrm{c}}\right)=\langle\mathrm{x},(0.5,0.4),(0.2,0.3)\rangle$ is not an IFGCS in $\mathrm{X}$. Hence $\mathrm{f}$ is not an IFG continuous mapping.

Theorem 3.11: Every IFGS continuous mapping is an IFraS continuous mapping but not conversely.

Proof: Let $\mathrm{f}:(\mathrm{X}, \tau) \rightarrow(\mathrm{Y}, \sigma)$ be an IFG continuous mapping. Let $\mathrm{A}$ be an IFCS in $\mathrm{Y}$. Then by hypothesis $\mathrm{f}^{-1}(\mathrm{~A})$ is an IFGCS in X. Since every IFGCS is an IF $\pi$ GSCS, $\mathrm{f}^{-1}(\mathrm{~A})$ is an IF-GSCS in $\mathrm{X}$. Hence $\mathrm{f}$ is an IFrGS continuous mapping.

Example 3.12: Let $X=\{a, b\}, Y=\{u, v\}$ and $G_{1}=\langle x$, $(0.5,0.6),(0.2,0.2)\rangle, \mathrm{G}_{2}=\langle\mathrm{y},(0.6,0.6),(0.3,0.2)\rangle$. Then $\tau$ $=\left\{0_{\sim}, \mathrm{G}_{1,1} 1_{\sim}\right.$ and $\sigma=\left\{0_{\sim}, \mathrm{G}_{2,1}\right\}$ are IFTs on $\mathrm{X}$ and $\mathrm{Y}$ respectively. Define a mapping $\mathrm{f:}(\mathrm{X}, \tau) \rightarrow(\mathrm{Y}, \sigma)$ by $\mathrm{f}(\mathrm{a})=\mathrm{u}$ and $f(b)=v$. The IFS $G_{2}{ }^{c}=\langle y,(0.3,0.2),(0.6,0.6)\rangle$ is IFCS in Y. Then $\mathrm{f}^{-1}\left(\mathrm{G}_{2}{ }^{\mathrm{c}}\right)$ is IF-GSCS in $\mathrm{X}$ but not IFGSCS in $\mathrm{X}$. Then $\mathrm{f}$ is IF-GS continuous mapping but not an IFGS continuous mapping

Theorem 3.13: Every IF $\alpha \mathrm{G}$ continuous mapping is an IFrGS continuous mapping but not conversely. 
Proof: Let $\mathrm{f}:(\mathrm{X}, \tau) \rightarrow(\mathrm{Y}, \sigma)$ be an IF $\alpha \mathrm{G}$ continuous mapping. Let $\mathrm{A}$ be an IFCS in $\mathrm{Y}$. Then by hypothesis $\mathrm{f}^{-1}(\mathrm{~A})$ is an IF $\alpha$ GCS in X. Since every IF $\alpha$ GCS is an IFGSCS and every IFGSCS is an IFmGSCS, $\mathrm{f}^{-1}(\mathrm{~A})$ is an IF"GSCS in $\mathrm{X}$. Hence $f$ is an IFrGS continuous mapping.

Example 3.14: Let $X=\{a, b\}, Y=\{u, v\}$ and $G_{1}=\langle x$, $(0.4,0.6),(0.2,0.2)\rangle, \mathrm{G}_{2}=\langle\mathrm{y},(0.6,0.2),(0.4,3)\rangle$.Then $\tau=$ $\left\{0_{\sim}, \mathrm{G}_{1}, 1_{\sim}\right\}$ and $\sigma=\left\{0_{\sim}, \mathrm{G}_{2}, 1_{\sim}\right\}$ are IFTs on $\mathrm{X}$ and $\mathrm{Y}$ respectively. Define a mapping $\mathrm{f}:(\mathrm{X}, \tau) \rightarrow(\mathrm{Y}, \sigma)$ by $\mathrm{f}(\mathrm{a})=\mathrm{u}$ and $\mathrm{f}(\mathrm{b})=\mathrm{v}$. The IFS $\mathrm{G}_{2}{ }^{\mathrm{c}}=\langle\mathrm{y},(0.4,0.3),(0.6,0.2)\rangle$ is IFCS in $\mathrm{Y}$. Then $\mathrm{f}^{-1}\left(\mathrm{G}_{2}{ }^{\mathrm{c}}\right)$ is IF-GSCS in $\mathrm{X}$ but not IF $\alpha$ GCS in $X$. Then $f$ is $I F-G S$ continuous mapping but not an IF $\alpha G$ continuous mapping.

Remark 3.15: IFP continuous mapping and IF-GS continuous mapping are independent to each other.

Example 3.16: Let $X=\{a, b\}, Y=\{u, v\}$ and $G_{1}=\langle x$, $(0.2,0.4),(0.5,0.4)\rangle, G_{2}=\langle x,(0.1,0.3),(0.3,0.4)\rangle, G_{3}=\langle x$, $(0.1,0.3),(0.5,0.4)\rangle, \mathrm{G}_{4}=\langle\mathrm{x},(0.2,0.4),(0.3,0.4)\rangle, \mathrm{G}_{5}=\langle\mathrm{x}$, $(0.4,0.4),(0.3,0.4)\rangle, \mathrm{G}_{6}=\langle\mathrm{y},(0.5,0.4),(0,0.3)\rangle$. Then $\tau=\left\{0_{\sim}, \mathrm{G}_{1}, \mathrm{G}_{2}, \mathrm{G}_{3}, \mathrm{G}_{4}, \mathrm{G}_{5}, 1_{\sim}\right\}$ and $\sigma=\left\{0_{\sim}, \mathrm{G}_{6}, 1_{\sim}\right\}$ are IFTs on $\mathrm{X}$ and $\mathrm{Y}$ respectively. Define a mapping $\mathrm{f}:(\mathrm{X}, \tau) \rightarrow(\mathrm{Y}, \sigma)$ by $f(a)=u$ and $f(b)=v$. Then $f$ is IFP continuous mapping but not an IF\#GS continuous mapping since $\mathrm{G}_{6}{ }^{\mathrm{c}}=\langle\mathrm{y},(0,0.3)$, $(0.5,0.4)\rangle$ is an IFCS in $Y$ but $f^{-1}\left(G_{6}{ }^{c}\right)=\langle x,(0,0.3),(0.5$, $0.4)\rangle$ is not IFraSCS in X.

Example 3.17: Let $X=\{a, b\}, Y=\{u, v\}$ and $G_{1}=\langle x$, $(0.4,0.2),(0.6,0.7)\rangle, \mathrm{G}_{2}=\langle\mathrm{y},(0.6,0.7),(0.4,0.2)\rangle$. Then $\tau=$ $\left\{0_{\sim}, \mathrm{G}_{1}, 1_{\sim}\right\}$ and $\sigma=\left\{0_{\sim}, \mathrm{G}_{2,} 1_{\sim}\right\}$ are IFTs on $\mathrm{X}$ and $\mathrm{Y}$ respectively. Define a mapping $\mathrm{f}:(\mathrm{X}, \tau) \rightarrow(\mathrm{Y}, \sigma)$ by $\mathrm{f}(\mathrm{a})=\mathrm{u}$ and $f(b)=v$. Then $f$ is IF-GS continuous mapping but not an IFP continuous mapping since $\mathrm{G}_{2}{ }^{\mathrm{c}}=\langle\mathrm{y},(0.4,0.2),(0.6,0.7)$ \rangle is an IFCS in $\mathrm{Y}_{\text {but }} \mathrm{f}^{-1}\left(\mathrm{G}_{2}{ }^{\mathrm{c}}\right)=\langle\mathrm{x},(0.4,0.2),(0.6,0.7)\rangle$ is not IFPCS in $\mathrm{X}$.

Remark 3.18: IF $\gamma$ continuous mapping and IFrGS continuous mapping are independent to each other.

Example 3.19: Let $X=\{a, b\}, Y=\{u, v\}$ and $G_{1}=\langle x$, $(0.1,0.3),(0.4,0.3)\rangle, G_{2}=\langle x,(0,0.2),(0.2,0.3)\rangle, G_{3}=\langle x$, $(0,0.2),(0.4,0.3)\rangle, \mathrm{G}_{4}=\langle\mathrm{x},(0.1,0.3),(0.2,0.3)\rangle, \quad \mathrm{G}_{5}=\langle$ $\mathrm{x},(0.3,0.3),(0.2,0.3)\rangle, \mathrm{G}_{6}=\langle\mathrm{y},(0.3,0.4),(0,0.1)\rangle$. Then $\tau=\left\{0_{\sim}, \mathrm{G}_{1}, \mathrm{G}_{2}, \mathrm{G}_{3}, \mathrm{G}_{4}, \mathrm{G}_{5}, 1_{\sim}\right\}$ and $\sigma=\left\{0_{\sim}, \mathrm{G}_{6}, 1_{\sim}\right\}$ are IFTs on $\mathrm{X}$ and $\mathrm{Y}$ respectively. Define a mapping $\mathrm{f}:(\mathrm{X}, \tau) \rightarrow$ $(\mathrm{Y}, \sigma)$ by $\mathrm{f}(\mathrm{a})=\mathrm{u}$ and $\mathrm{f}(\mathrm{b})=\mathrm{v}$. Then $\mathrm{f}$ is IF $\gamma$ continuous mapping but not an IF-GS continuous mapping since $\mathrm{G}_{6}{ }^{\mathrm{c}}=\langle$ $\mathrm{y},(0,0.1),(0.3,0.4)\rangle$ is an IFCS in $\mathrm{Y}$ but $\mathrm{f}^{-1}\left(\mathrm{G}_{6}{ }^{\mathrm{c}}\right)=\langle\mathrm{x},(0$, $0.1),(0.3,0.4)\rangle$ is not IFraSCS in X.

Example 3.20: Let $X=\{a, b\}, Y=\{u, v\}$ and $G_{1}=\langle x$, $(0.5,0.1),(0.5,0.9)\rangle, \mathrm{G}_{2}=\langle\mathrm{y},(0.2,0.1),(0.7,0.8)\rangle$. Then $\tau=$ $\left\{0_{\sim}, \mathrm{G}_{1}, 1_{\sim}\right\}$ and $\sigma=\left\{0_{\sim}, \mathrm{G}_{2}, 1_{\sim}\right\}$ are IFTs on $\mathrm{X}$ and $\mathrm{Y}$ respectively. Define a mapping $\mathrm{f}:(\mathrm{X}, \tau) \rightarrow(\mathrm{Y}, \sigma)$ by $\mathrm{f}(\mathrm{a})=\mathrm{u}$ and $f(b)=v$. Then $f$ is IFmGS continuous mapping but not an IF $\gamma$ continuous mapping since $\mathrm{G}_{2}{ }^{\mathrm{c}}=\langle\mathrm{y},(0.7,0.8),(0.2,0.1)\rangle$ is an IFCS in $\mathrm{Y} \mathrm{but}^{-1}\left(\mathrm{G}_{2}{ }^{\mathrm{c}}\right)=\langle\mathrm{x},(0.7,0.8),(0.2,0.1)\rangle$ is not IF $\gamma \mathrm{CS}$ in $\mathrm{X}$.

The relations between various types of intuitionistic fuzzy continuity are given in the following diagram. In this diagram 'cts' means continuous.
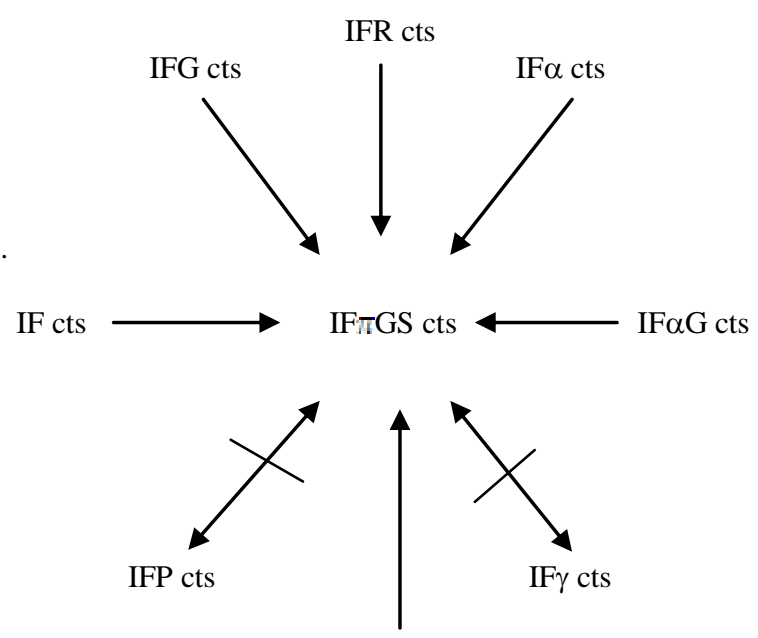

IFGS cts

Fig.1 Relation between intuitionistic fuzzy $\pi$ - generalized semi continuous mappings and other existing intuitionistic fuzzy mappings.

In this diagram by " $\mathrm{A} \longrightarrow \mathrm{B}$ " we mean $\mathrm{A}$ implies B but not conversely and " $\longrightarrow$ B" means A and B are

independent of each other.

None of them is reversible

Theorem 3.21: A mapping f: $\mathrm{X} \rightarrow \mathrm{Y}$ is IF"GS continuous then the inverse image of each IFOS in $\mathrm{Y}$ is an IFrGSOS in $\mathrm{X}$.

Proof: Let A be an IFOS in Y. This implies $A^{c}$ is IFCS in Y. Since $f$ is IF-GS continuous, $f^{-1}\left(A^{c}\right)$ is IF-GSCS in $X$. Since $\mathrm{f}^{-1}\left(\mathrm{~A}^{\mathrm{c}}\right)=\left(\mathrm{f}^{-1}(\mathrm{~A})\right)^{\mathrm{c}}, \mathrm{f}^{-1}(\mathrm{~A})$ is an IF-GSOS in $\mathrm{X}$.

Theorem 3.22: Let $\mathrm{f}:(\mathrm{X}, \tau) \rightarrow(\mathrm{Y}, \sigma)$ be an $\mathrm{IF} \pi \mathrm{GS}$ continuous mapping, then $\mathrm{f}$ is an IF continuous mapping if $\mathrm{X}$ is an $\operatorname{IF} \pi \mathrm{T}_{1 / 2}$ space.

Proof: Let A be an IFCS in Y. Then $\mathrm{f}^{-1}(\mathrm{~A})$ is an IF"GSCS in $X$, since $f$ is an IF-GS Continuous. Hence $X$ is an IF $\pi T_{1 / 2}$ space, $\quad \mathrm{f}^{-1}(\mathrm{~A})$ is an IFCS in $\mathrm{X}$. Hence $\mathrm{f}$ is an IF continuous mapping. 
Theorem 3.23: Let $\mathrm{f}:(\mathrm{X}, \tau) \rightarrow(\mathrm{Y}, \sigma)$ be an IFmGS continuous function, then $\mathrm{f}$ is an IFG continuous mapping if $\mathrm{X}$ is an $\operatorname{IF} \pi \mathrm{gT}_{1 / 2}$ space.

Proof: Let A be an IFCS in Y. Then $\mathrm{f}^{-1}(A)$ is an IF-GSCS in $X$, by hypothesis. Since $X$ is an $\operatorname{IF}_{\pi g T_{1 / 2}}$ space, $f^{-1}(A)$ is an IFGCS in $\mathrm{X}$. Hence $\mathrm{f}$ is an IFG continuous mapping.

Theorem 3.24: Let $\mathrm{f}:(\mathrm{X}, \tau) \rightarrow(\mathrm{Y}, \sigma)$ be an IF"GS continuous mapping and $\mathrm{g}:(\mathrm{Y}, \sigma) \rightarrow(\mathrm{Z}, \delta)$ is IF continuous, then $\mathrm{g}$ o $\mathrm{f}:(\mathrm{X}, \tau) \rightarrow(\mathrm{Z}, \delta)$ is an IF-GS continuous.

Proof: Let A be an IFCS in Z. Then $\mathrm{g}^{-1}(\mathrm{~A})$ is an IFCS in Y, by hypothesis. Since $\mathrm{f}$ is an IF-GS continuous mapping, $\mathrm{f}^{-1}(\mathrm{~g}$ ${ }^{1}(\mathrm{~A})$ is an IF-GSCS in $\mathrm{X}$. Hence $\mathrm{g}$ o $\mathrm{f}$ is an IF-GS continuous mapping.

\section{CONCLUSION}

In this paper we have introduced intuitionistic fuzzy $\pi$-generalized semi continuous mappings and studied some of its basic properties. Also we have studied the relationship between intuitionistic fuzzy generalized continuous mappings and some of the intuitionistic fuzzy continuous mappings already exist.

\section{REFERENCES}

[1] K.T.Atanassov, Intuitionistic fuzzy sets, Fuzzy Sets and Systems, 20 (1986), 87-96.

[2] C.L.Chang, Fuzzy topological spaces, J. Math. Anal. Appl., 24, 1968, 182-190.

[3] D.Coker, An introduction to fuzzy topological space, Fuzzy sets and systems, 88, 1997, 81-89.
[4] M.E.El-Shafhi, and A. Zhakari., Semi generalized continuous mappings in fuzzy topological spaces, J. Egypt. Math. Soc. 15(1)(2007), 57-67.

[5] H.Gurcay, D.Coker and A.Haydar, On fuzzy continuity in intuitionistic fuzzy topological spaces, jour. of fuzzy math., 5(1997), 365-378.

[6] I.M.Hanafy, Intuitionistic fuzzy continuity, Canad. Math Bull. XX(2009), 1-11.

[7] Joung Kon Jeon, Young Bae Jun, and Jin Han Park, Intuitionistic fuzzy alpha continuity and intuitionistic fuzzy pre continuity, International Journal of Mathematics and Mathematical Sciences, 19 (2005), 3091-3101.

[8] S.Maragathavalli and K.Ramesh ,Intuitionistic fuzzy II- generalized semi closed sets, Advances in Theoretical and Applied Sciences, 1 (2012), 33-42.

[9] K.Sakthivel, Intuitionistic fuzzy alpha generalized continuous mappings and intuitionistic fuzzy alpha generalized irresolute mappings, Applied Mathematical Sciences, 4 (2010), $1831-1842$.

[10] R.Santhi, and K.Sakthivel., Intuitionistic Fuzzy Generalized Semi Continuous mappings, Advances in Theoretical and Applied Mathematics, 5(2009),73-82.

[11] S.S.Thakur, and Rekha Chaturvedi, Regular generalized closed sets in intuitionistic fuzzy topological spaces, Universitatea Din Bacau, Studii Si Cercetari Stiintifice, Seria: Matematica, 16 (2006), 257-272.

[12] Young Bae Jun and Seok- Zun Song, Intuitionistic fuzzy semi-pre open sets and Intuitionistic semi-pre continuos mappings, jour. of Appl. Math and computing, 19(2005), 467-474.

[13] L. A Zadeh, Fuzzy sets, Information and control, 8 (1965) 338-353. 